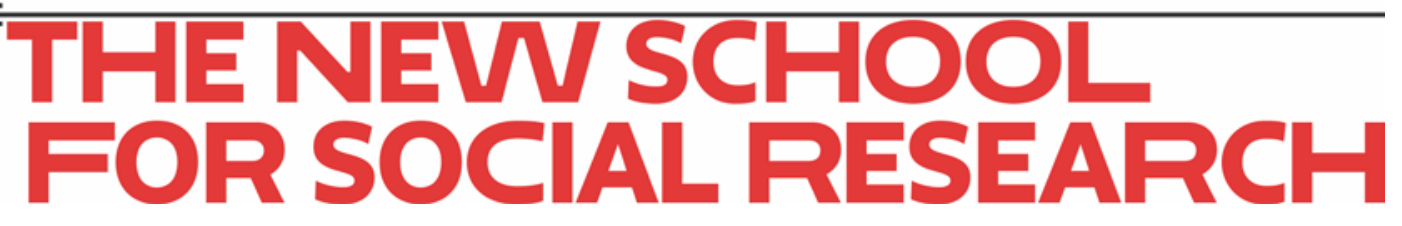

Mark Setterfield and Joana David

Avritzer

\title{
Hysteresis in the normal rate of capacity utilization: a behavioural explanation
}

June 2019

Working Paper 07/2019

Department of Economics

The New School for Social Research 


\title{
Hysteresis in the normal rate of capacity utilization: a behavioural explanation
}

\author{
Mark Setterfield ${ }^{\dagger}$ and Joana David Avritzer ${ }^{\ddagger}$
}

June 11, 2019

\begin{abstract}
Kaleckians describe a normal rate of capacity utilization that is subject to hysteresis effects. This means that the normal rate varies directly with the actual rate of capacity utilization, ensuring that steady-state equilibrium conditions in the Kaleckian model are fully adjusted (the actual and normal rates of capacity utilization are equalized) but without this last condition implying that the rate of capacity utilization is constant in the long run. The relationship between distribution and growth unique to the Kaleckian model is thus preserved. The hysteresis mechanism has been criticized from various quarters, however, these criticisms focusing on its alleged lack of behavioural foundations. This paper shows that consistent with the stylized facts, variation in the normal rate of capacity utilization in response to variation in the actual capacity utilization rate can be derived from the links between both variables and the volatility of the macroeconomic environment - volatility, in the presence of fundamental uncertainty, being an important reason why firms deliberately under-utilize capacity (even in the long run) in the first place. The result is an empirically-grounded behavioural foundation for hysteresis in the normal rate of capacity utilization.
\end{abstract}

JEL codes: E11, E12, O41

Keywords: Normal rate of capacity utilization, Harrodian instability, hysteresis, Kaleckian growth theory

\section{Introduction}

According to Kaleckians, the normal rate of capacity utilization that influences corporate investment decisions is subject to hysteresis, with variations in the normal rate arising in

${ }^{\dagger}$ New School for Social Research; email mark.setterfield@newschool.edu

${ }_{\ddagger}^{\ddagger}$ New School for Social Research; email davij032@newschool.edu 
response to deviations of the actual rate of capacity utilization from the normal rate (Lavoie, 1995, 1996, 2010; Dutt, 1997, 2010; Cassetti, 2006; Commendatore, 2006) 1 A Authors in the Classical and neo-Keynesian traditions resist this claim. In particular, in the course of reasserting the Classical/neo-Keynesian position that the normal rate of capacity utilization is exogenously given, Skott (2012) argues that the Kaleckian hysteresis argument lacks proper behavioural foundations. The principal objective of this paper is to revisit this debate, with a view to establishing a behavioural theory of hysteretic variation in the normal rate of capacity utilization. It will be shown that the volatility of the macroeconomic environment, as captured by the variance of the rate of capacity utilization, plays a crucial role in linking changes in the normal rate of capacity utilization to changes in the actual rate. This, in turn, links the behavioural foundations for hysteresis in the normal rate of capacity utilization to the behavioural foundations of the normal rate itself.

The rest of the paper is organized as follows. Section 2 reviews the role of the rate of capacity utilization in Kaleckian and Classical/neo-Keynesian investment theory. Particular emphasis is placed on the Kaleckian theory of hysteresis in the normal rate of capacity utilization, and criticisms of this theory due to Skott (2012). In section 3, we review various stylized facts pertaining to the behaviour of the rate of capacity utilization in the US. These stylized facts play a prominent role in advising the behavioural theory of hysteresis in the normal rate of capacity utilization developed in section 4 , in which the variance of the rate of capacity utilization plays a crucial role. Finally, section 5 concludes.

\footnotetext{
${ }^{1}$ Use of term hysteresis as a synonym for path dependence is by no means universally popular Amable et al. 1993, 1994). In Kaleckian macroeconomics, however, it has become established practice to refer to situations in which variations in the normal rate of capacity utilization occur as a result of deviations of the actual rate of capacity utilization from the normal rate as involving hysteresis, and we adhere to this convention in what follows.
} 


\section{The normal rate of capacity utilization: exogenously given or hysteretic?}

Kaleckian macroeconomics posits variation in the actual (equilibrium) rate of capacity utilization, even in the long run. According to Classical and neo-Keynesian theory, however, the long-run capacity utilization rate is constant at a fixed normal rate. In Classical/neoKeynesian theory, the actual rate of capacity utilization can differ from its normal rate in the short run, but must return to the normal rate in the long run if the economy is to achieve a "fully-adjusted position".

Kaleckians counter that capacity utilization can vary in the long run, even when there

exists a normal rate of capacity utilization. A variety of reasons are given for this (Hein et al. 2012), one of which involves postulating "hysteresis" in the normal rate, the latter understood as a historically-grounded rule of thumb that rises and falls with the actual rate of capacity utilization (Lavoie, 1995, 1996, 2010, Dutt, 1997, 2010; Cassetti, 2006; Commendatore, 2006). Skott (2012) and Nikiforos (2016) argue that while analytically sound, the hysteresis mechanism lacks adequate behavioural foundations.

To bring this debate into focus, and following Hein et al. (2011), we begin with a Kaleckian model represented by the equations:

$$
\begin{gathered}
g^{s}=s_{\pi} \frac{\pi u}{v}, \quad s_{\pi}>0 \\
g^{i}=\gamma+\gamma_{u}\left(u-u_{n}\right), \quad \gamma>0, \quad \gamma_{u}>0
\end{gathered}
$$

In the first equation $g^{s}$, the rate of accumulation consistent with the equality of investment and savings, is defined as a function of $\pi$, the profit share of income, $u$, the capacity utilization rate, $v$, the full-capacity capital-output ratio, and $s_{\pi}$, the propensity to save out of profits. The second equation describes the actual rate of investment, $g^{i}$, as a function of a parameter 
$\gamma$ (representing an assessment of the trend of growth of sales) and of deviations of the capacity utilization rate from its normal level, $u_{n}$. The hypothesis underlying this last equation is that whenever the rate of capacity utilization is above its normal level, firms will attempt to bring it back towards its normal rate by accumulating capital at a rate that exceeds the assessed trend rate of growth of sales.

In the system of equations (1) and (2) equilibrium $\left(g^{i}=g^{s}\right)$ implies the following solutions for capacity utilization, $u^{*}$, and the rate of accumulation, $g^{*}$ :

$$
\begin{aligned}
u^{*} & =\frac{\gamma-\gamma_{u} u_{n}}{\frac{s_{\pi} \pi}{v}-\gamma_{u}} \\
g^{*} & =\frac{\gamma-\gamma_{u} u_{n}}{1-\frac{v \gamma_{u}}{s_{\pi} \pi}}
\end{aligned}
$$

These solutions show that the Kaleckian model allows for an equilibrium in which $u$ differs from $u_{n}$. Furthermore, in the case of an initial discrepancy between the actual rate of capacity utilization and its normal rate, investment may respond in a manner that exacerbates the original discrepancy, giving rise to Harrodian instability. This is illustrated in Figure 1. If, because of an initial shock to $\gamma$ due, for example, to a change in animal spirits, the investment function shifts upward to $g_{i}^{\prime}$, a new equilibrium with $u^{\prime}>u_{n}$, will emerge. But if with $u>u_{n}$ firms' animal spirits are buoyed and they make a new higher assessment of the trend growth rate of sales, the $\gamma$ parameter increases again, shifting the investment function even further up to $g_{i}^{\prime \prime}$ and the capacity utilization to a new equilibrium at $u^{\prime \prime}$. This means that as long as $u_{t}>u_{n}$ for any $t$, the parameter $\gamma$ in the investment function will be susceptible to constant increase, pushing capacity utilization ever further above its normal rate. The resulting Harrodian instability will persist unless an additional mechanism brings capacity utilization back to its normal level. In fact, several mechanisms have been proposed that purport to address this issue. 
Figure 1 - Harrodian Instability

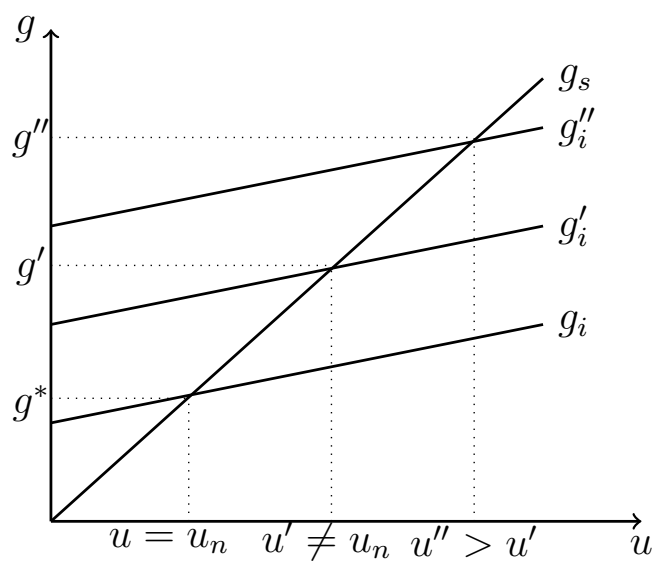

\subsection{Classical/neo-Keynesian mechanisms}

\subsubsection{Adjustments operating through a shift in the savings function}

The Cambridge price mechanism, the endogenous retention ratio mechanism, and the supermultiplier mechanism all postulate adjustments in the savings function. The first mechanism, emphasized by authors such as Harcourt (1972), Eichner (1976), and Kaldor (1985), assumes that whenever firms see that the actual rate of utilization of their capacity is higher than its normal level they will raise their profit margin and hence the profit share. The second mechanism, suggested by Shaikh (2009), is derived from assuming that the savings function is made up of two components: the retention ratio of firms on profits, which is assumed to be endogenous to a discrepancy between the current rate of capacity utilization and its normal level; and the proportion of income that households save. Both mechanisms imply a change in the relation between $g_{s}$ and $u$ (through either $\pi$ or $s_{\pi}$ ) that will cause a rotation in the savings function whenever $u$ is different from its normal rate. As can be seen in Figure 2.a below, this rotation will eventually take capacity utilization back to its normal rate.

Finally, the supermultiplier argument is tied to an exogenous demand component. According to Lavoie (2016), following Freitas and Serrano (2015), the crucial point is that when 
there is an autonomous consumption expenditure component, the average propensity to save becomes endogenous and the savings function can then be rewritten as:

$$
g^{s}=s_{p} \frac{\pi u}{v}-z
$$

where $z=\frac{Z}{K}, Z$ is autonomous consumption spending by capitalists, and $K$ is the capital stock. In the supermultiplier, as both $\pi$ and $s_{\pi}$ are taken as exogenously given, adjustments occur through $z$ and, consequently, a change in intercept of the $g^{s}$ schedule. Meanwhile, the equilibrium rate of growth is given by $g_{z}$, the growth rate of autonomous consumption. Therefore, if $s_{\pi}$ decreases due to an exogenous shock, this will first shift the $g_{s}$ schedule to $g_{s}^{\prime}$, which will increase capacity utilization to $u^{\prime}$ and the accumulation rate to $g^{\prime}>g_{z}$. However, whenever $g>g_{z}, z$ must be falling, which results in a shift of $g_{s}^{\prime}$ until it reaches $g_{s}^{\prime \prime}$, at which point $g=g_{z}$ and $u=u_{n}$. This dynamic is shown in Figure 2.b below. Comparing Figures 2.a and 2.b makes clear that while the first two mechanisms imply a rotation in $g_{s}$ to reach a fully adjusted position, in the supermultiplier the adjustment occurs through a parallel shift in the $g_{s}$ schedule.

Figure 2.a - Adjustment in $g^{s}$ : the Cambridge/Classical Mechanism

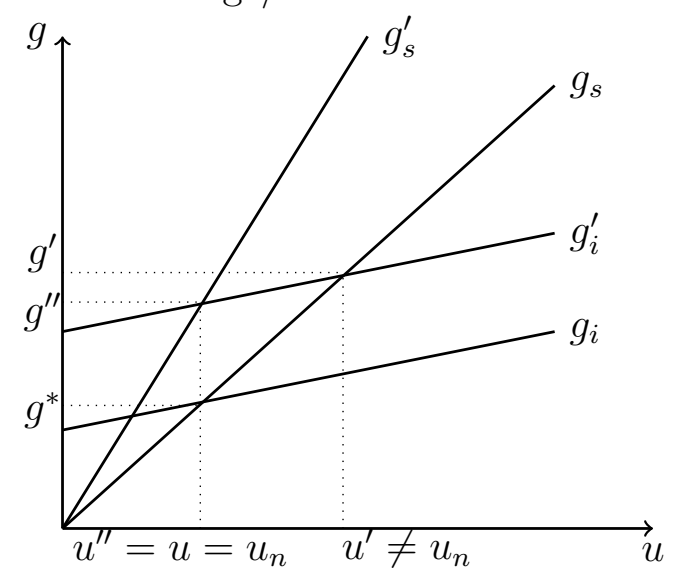

Figure 2.b - Adjustment in $g^{s}$ : the Supermultiplier Mechanism

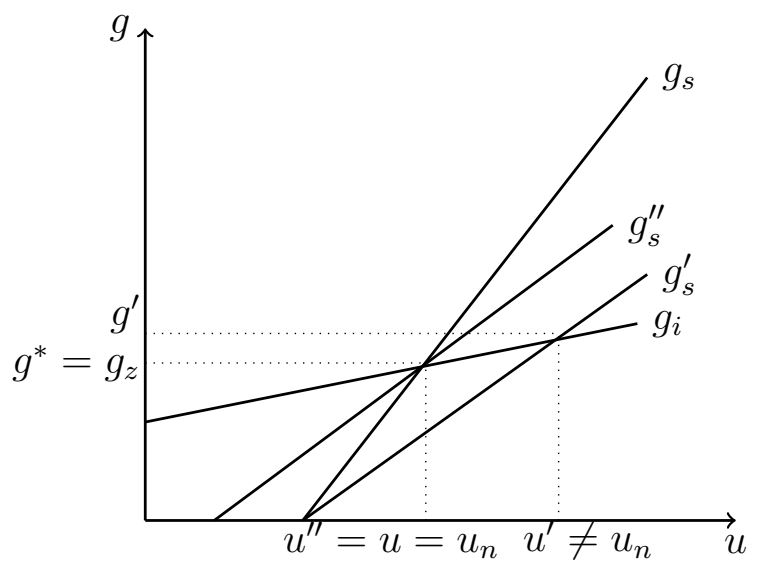




\subsubsection{Adjustment operating through a shift in the investment function}

Three mechanisms, due to Dumenil and Levy (1999), Shaikh (2009) and Skott (2010), suggest adjustment through the investment schedule. The mechanism suggested by Dumenil and Levy (1999) assumes that as the actual utilization rate exceeds its normal level, monetary authorities fearing inflation will tighten monetary policy. As a result, the parameter $\gamma$ of the investment function will shift downwards until the capacity utilization rate converges back to its normal rate. The mechanism suggested by Skott (2010), meanwhile, also operates through an adjustment in the $\gamma$ parameter. This time, however, the shift in $\gamma$ is explained by capitalists' fear of inflation, reducing their assessed trend growth rate of the economy. Finally, the Shaikh (2009) mechanism postulates adjustment through the $\gamma$ parameter, but this time explained by capitalists shifting the investment function because they have perfect foresight. More specifically, because capitalists have perfect foresight, it is assumed that the assessed growth rate of the economy becomes not only a positive function of the actual growth rate of the economy, but also a negative function of the difference between $u$ and $u_{n}$. All three mechanisms can be represented as a shift in the intercept of the investment function, as shown in the Figure 3 below, which takes the capacity utilization back to its normal rate.

Figure 3 - Adjustment in $g^{i}$ : the Dumenil/Levy,

Skott and Shaikh Mechanisms

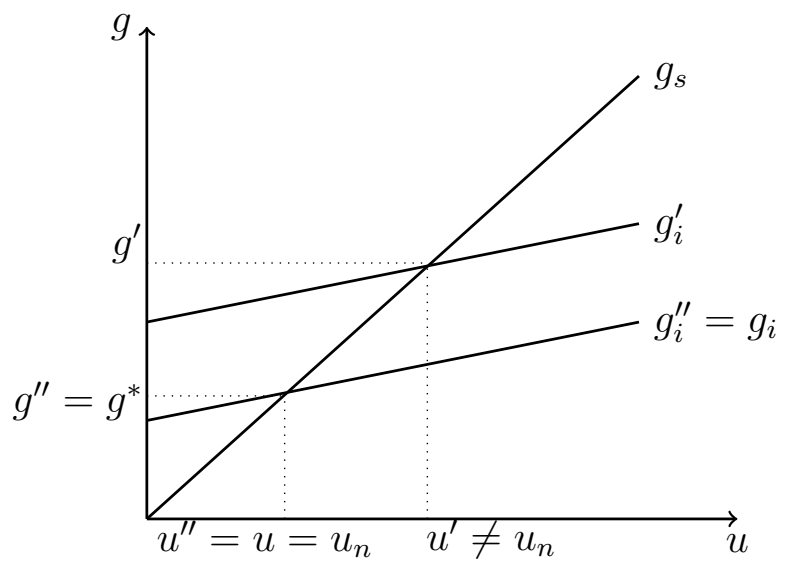




\section{$2.2 \quad$ Kaleckian mechanisms}

The adjustment mechanisms surveyed thus far assume the existence of a unique normal capacity utilization rate and so eliminate the paradoxes of costs and thrift as features of steady-state growth in the process of achieving a fully-adjusted position 2 According to Kaleckians, however, the capacity utilization rate can vary in the long run even when there exists a normal rate of capacity utilization and steady-state growth is fully adjusted. The following mechanisms address the onset of Harrodian instability when $u \neq u_{n}$ without eliminating the paradoxes of cost and thrift in the long run.

\subsubsection{Mechanisms justifying a capacity utilization rate different from its normal rate}

The "multiple targets" and "tolerable interval" arguments suggest that the actual rate of capacity utilization may permanently differ from any single-valued normal rate of capacity utilization. The first mechanism appears in Lavoie (1992, pp.417-21), Lavoie (2002, 2003), and Dallery and van Treeck (2011) and is summarized by Hein et al. (2012, pp.148-154), who argue that the existence of two types of conflicts - between managers who seek growth and shareholders who seek profitability, and between firms and workers over profits and wages may result in a capacity utilization rate that is consistently different from its normal rate, even in the long run. The argument is that in a world where different groups within the firm have different objectives, even though a convention is formed as to what is the normal rate of capacity utilization, this may never be reached due to irreconcilable conflicts of interest. In this case, even if $u$ is higher than $u_{n}$ in the long run, firms will understand that this is due to conflicts of interest and will not be provoked into the behavioural change that gives rise

\footnotetext{
$\sqrt[2]{\text { Lavoie }(2016)}$ argues that, with the supermultiplier mechanism, the paradox of thrift and the paradox of costs still hold in the short run, in terms of level effects on income, and in the long run, in terms of the average growth rates over the duration of the traverse. Nonetheless, this is not the same as arguing, as is conventional in Kaleckian theory, that steady state growth is influenced by income distribution.
} 
to Harrodian instability. The capacity utilization rate will simply remain at $u^{\prime}$, as shown in Figure 4, without this resulting in the onset of Harrodian instability.

The second mechanism, developed by Dutt (2010) and Setterfield (2019) $!^{3}$ suggests that instead of taking one specific value as the normal rate of capacity utilization, firms have a tolerable interval of variation in the capacity utilization rate that they consider normal. Furthermore, only variations of actual capacity utilization that lie outside this tolerable interval will provoke behavioural change on the part of firms. Consequently, if capacity utilization stays in the tolerable interval $\bar{u}_{n}-c<u<\bar{u}_{n}+c$, where $c$ is a conventional constant, then it can differ from the fixed value $\bar{u}_{n}$ without this provoking Harrodian instability. This mechanism is also illustrated in Figure 4.

\subsubsection{Hysteresis}

Amadeo (1986), Lavoie 1995, 1996, 2010), Lavoie et al. (2004) and Dutt (1997, 2010) suggest a mechanism which assumes that the normal rate of capacity utilization is influenced by past values of the actual rate of utilization 4 In other words, the normal rate of capacity utilization becomes endogenous to the actual rate, making for a "hysteretic" normal rate of capacity utilization. This idea has a long pedigree - indeed, it can be traced back to Robinson 1956, pp.186-90) - and can be represented by the following equation:

$$
\Delta u_{n}=\mu\left(u-u_{n}\right), \quad \mu>0
$$

The hysteresis mechanism suggests that entrepreneurs raise/lower the normal capacity utilization rate whenever the actual rate exceeds/falls short of the normal rate. This is illustrated in Figure 5. It is possible to see that unlike the previous mechanisms illustrated in Figure 4, where $u$ is essentially unresponsive to $u \neq u_{n}$ (at least within bounds), with hys-

\footnotetext{
${ }^{3}$ See also Dutt (1990) and Lavoie (1992, pp.327-32, 417-22) for earlier discussions of the normal rate of capacity utilization as an interval rather than a single value.

${ }^{4}$ See also Cassetti (2006) and Commendatore (2006).
} 
teresis the economy unequivocally achieves a fully adjusted position but $u$ is, nevertheless, variable in the long run.

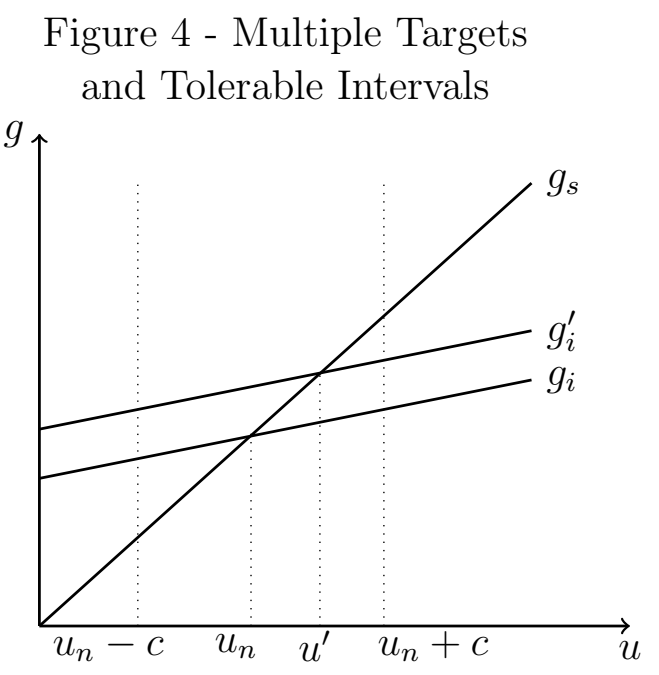

Graph 5 - Hysteresis

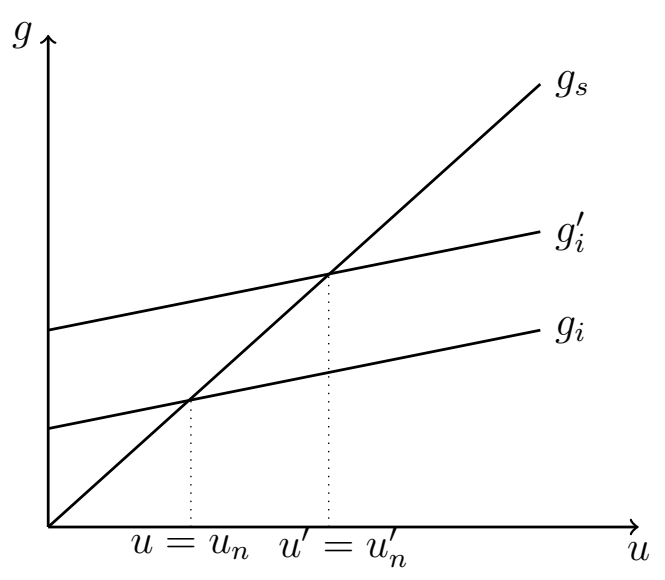

\subsection{Critique of the hysteresis mechanism}

Of all the mechanisms discussed above, only hysteresis provides a solution to the Harrodian instability problem by creating a long-run steady-state outcome that is unequivocally fullyadjusted and is characterized by the paradoxes of cost and thrift. This singles it out as an adjustment mechanism of some consequence in the broader context of heterodox theories of growth and distribution. The idea of a hysteretic normal rate of capacity utilization has nevertheless been criticized, in particular by Skott (2012) and Nikiforos (2016). The Skott (2012) critique - as amplified by Nikiforos (2016) - can be divided into four parts.

First, there is the criticism that the hysteresis mechanism lacks an adequate behavioural foundation. . $^{5}$ According to Skott (2012), from a purely mathematical perspective the argument is correct. However, he argues that Amadeo (1986), Lavoie (1995), and Dutt (1997) provide no clear explanation of the sort of behaviour that would result in equation (5). Skott (2012) argues that neither Amadeo (1986) nor Lavoie 1995) go beyond stating the function-

\footnotetext{
${ }^{5}$ See also Nikiforos (2016, pp.443-4).
} 
ing of the adjustment process in (5). Credit is given to Dutt (1997) for providing more detail as to how the adjustment process works, but this only brings us to the second criticism, which is specific to the Dutt (1997) argument. Dutt (1997) suggests that firms reduce their normal rate of utilization if the expected threat of entry of new firms rises relative to the current actual rate of entry and, since the expected threat of entry and current rate of entry are proportional to the expected future and current actual rates of investment (respectively), this results in equation (5). To see this, first write:

$$
\dot{u}_{n}=\alpha(\gamma-g), \quad \alpha<0
$$

where (for example) $\gamma>g$ signals that expected future growth consistent with a fullyadjusted position $\left(g^{e}=\gamma\right)$ exceeds the current rate of growth $(g)$, and hence the expected future threat of entry of new firms exceeds the current rate of entry. With $\alpha<0$ this induces a reduction in the normal rate of capacity utilization $\left(\dot{u}_{n}<0\right)$ by firms seeking to use excess capacity as a credible threat to ward off new entrants. Substituting equation (2) into (6) yields:

$$
\dot{u}_{n}=\alpha\left(\gamma-\gamma-\gamma_{u}\left(u-u_{n}\right)\right)=-\alpha \gamma_{u}\left(u-u_{n}\right)
$$

It is clear by inspection that with $\mu=-\alpha \gamma_{u}>0$, this last expression is identical to equation (5). In other words, the Dutt (1997) mechanism in (6) means that $u<u_{n}$ induces a fall in $u_{n}$, and vice versa. In response, Skott (2012) argues that while it is plausible to link the normal rate of capacity utilization to strategic entry-deterrence considerations on the part of firms, it is not clear that either the threat of entry or the current entry rate are related to rates of accumulation (expected future and current actual, respectively) - in which case equation (6) lacks validity and the foundation for equation (5) in Dutt (1997) disappears ${ }^{6}$

\footnotetext{
${ }^{6}$ In fact, Skott (2012) makes a second criticism of equation (6), namely that it describes adjustments in the opposite direction of equation (5), suggesting that the normal rate of capacity utilization increases
} 
The third critique focuses on the Lavoie et al. (2004) argument that under uncertainty, the normal rate of capacity utilization must be a conventional variable, which is therefore adaptive. According to Skott (2012), even though $u_{n}$ may be influenced by conventions, it cannot be considered a purely conventional variable: "the presence of uncertainty and conventional elements does not mean that the desired utilization rate is a purely conventional variable" (Skott, 2012, p.121). There are, instead, more "fundamental" factors, that do not change with past experience, influencing the normal rate. Nikiforos (2016, pp.444) is more scathing about the treatment of $u_{n}$ as a convention, arguing that "it is hard to see why an entrepreneur will treat a decision of such importance for the profitability and survival of its firm merely as a convention."

Finally - and related to the previous criticism - Skott (2012) argues that there are limits to the adaptive behaviour suggested by Lavoie and others. He concedes that it seems reasonable to assume the presence of uncertainty and conventional elements in the notion of a normal capacity utilization rate, and that these conventional elements may be influenced by historical experience and strategic considerations. Nonetheless, he contends that the Amadeo-Dutt-Lavoie formulation requires not just the existence of some element of adaptation in conventional behaviour, but a process of adaptation that is both quantitatively fast and unbounded in order to guarantee the functioning of the mechanism described in equation (5).

As is evident, the central motif of the Skott (2012) critique is that the hysteresis mechanism in equation (5) lacks proper behavioural foundations. Ultimately, Kaleckian theory fails to provide "any reason why a negative demand shock and a decline in sales should make the firm think that the optimal degree of excess capacity has changed permanently" (Skott,

whenever the expected rate of growth exceeds its actual rate (i.e., $\gamma>g$ ). This claim is understandable since in the original formulation of equation (6) in Dutt (1997, p.247), $\alpha$ is described as the product of two positive parameters. It is clear form the accompanying text, however, that this is not the author's intention - hence the insistence that $\alpha<0$ in equation (6) above. This formal correction to the argument in Dutt (1997) was made by previously by Schoder (2012, pp.449-50). 
2012, p.123). In what follows, we will address this claim directly. As a precursor to this endeavour, we begin with a review of some stylized facts as they pertain to the behaviour of the capacity utilization rate in the US economy over the past six decades.

\section{The rate of capacity utilization: some stylized facts}

\subsection{Data and methods}

The data used for the empirical analysis in this section is taken from the Federal Reserve Board (FRB) database (FRED). It measures the capacity utilization rate of the US manufacturing sector, 1960-2015. Nikiforos (2016, pp.446-7) argues that this data does not, in fact, provide an appropriate measure of the capacity utilization rate - or at least a measure from which we can extract a trend value that can be suitably interpreted as the normal rate of capacity utilization. According to Nikiforos (2016), the FRB data does not measure capacity utilization relative to a physical maximum level of plant operation, but instead relative to a "normal" level of operation that can vary endogenously over time. This is due to the design of the survey questions on which basis the FRB capacity utilization data are collected. The upshot of all this, as Nikiforos (2016) demonstrates by way of a hypothetical example, is that reported capacity utilization can remain constant over time - giving rise to the appearance of a constant trend that can then be misinterpreted as a constant normal rate of capacity utilization - even as the normal rate of capacity utilization is, in fact, varying. Nikiforos (2016, p.446) is therefore given to conclude that the FRB data does not give us any information about the normal rate of capacity utilization.

Without taking issue with the essential substance of this argument, one can nevertheless take issue with the strength of the conclusion that Nikiforos $(2016)$ reaches: that data taken from the FRED provide no information about the normal rate of capacity utilization. This conclusion rests on the hypothesis that plant managers always and everywhere adhere to 
an interpretation of the US Census Bureau questionnaire (from which the FRB data is drawn) akin to that of Nikiforos (2016) himself. A weaker hypothesis is that such coincident interpretations occur some of the time, which results in the conclusion (still consistent with the essential thrust of Nikiforos's original argument) that the FRB data is likely prone to under-reporting variations in the normal rate of capacity utilization. The result is that the FRB data is biased against the null hypothesis that $u_{n t} \neq u_{n t-1}$. This, however, means only that we should be cautious of any rejection of the null: failure to reject the null hypothesis becomes a result in which researchers can invest more confidence, given the inherent bias in the data against this result. 7

Following Skott (2012, p.132) and others, we therefore derive the trend rate of capacity utilization derived from the FRB capacity utilization data using a Hodrick-Prescott (HP) filter, and use this trend as an appropriate estimate of the unobserved normal capacity utilization rate. The HP filter is not, of course, the only method of extracting unobserved trends from time series data, and is not without critics (Hamilton, 2018). Alternatives proposed by critics of the HP filter have, themselves, been subject to criticism, however, resulting in renewed enthusiasm for the HP filter in some quarters (Schüler, 2019). In what follows we set aside debate over the properties of alternative methods of filtering data. We note, however, that extracting unobserved trends from time series data is an inexact science, and conclusions drawn about the properties of an unobserved trend (and/or its relationship to other unobserved trends) may be sensitive to the use of different filtering techniques (Avritzer, 2019).

\footnotetext{
${ }^{7}$ The fact that Nikiforos's critique of the FRB data does not altogether preclude its use as a basis for inferring the normal rate of capacity utilization is, perhaps just as well, since: (i) the alternative data that Nikiforos (2016) recommends is quarterly rather than monthly and ends in 1984, thus offering only a limited number of observations for analysis; and (ii) our examination of this data reveals that, when compared to the descriptive statistics reported in the following sub-section, it has statistical properties that differ writ large from those of the FRB data commonly used in the empirical literature on the normal rate of capacity utilization. We refrain from further comment on this last issue here since it is beyond the scope of our paper, but it is clearly an issue to which all researchers in the post-Keynesian tradition need to be attentive.
} 
According to Skott (2012), the normal rate of capacity utilization is potentially timevarying, but any such time-variation is structurally determined, independently of variation in the actual rate of capacity utilization. Our working hypothesis is that, on the contrary, variation in the actual rate of capacity utilization induces variation in the normal rate.

\subsection{Descriptive statistics}

Figure 1 presents the data used in our empirical analysis. As a first stylized fact, note the appearance of a downward trend in the data (see also Blecker $(2016) ; \operatorname{Avritzer}(2019)) .8$

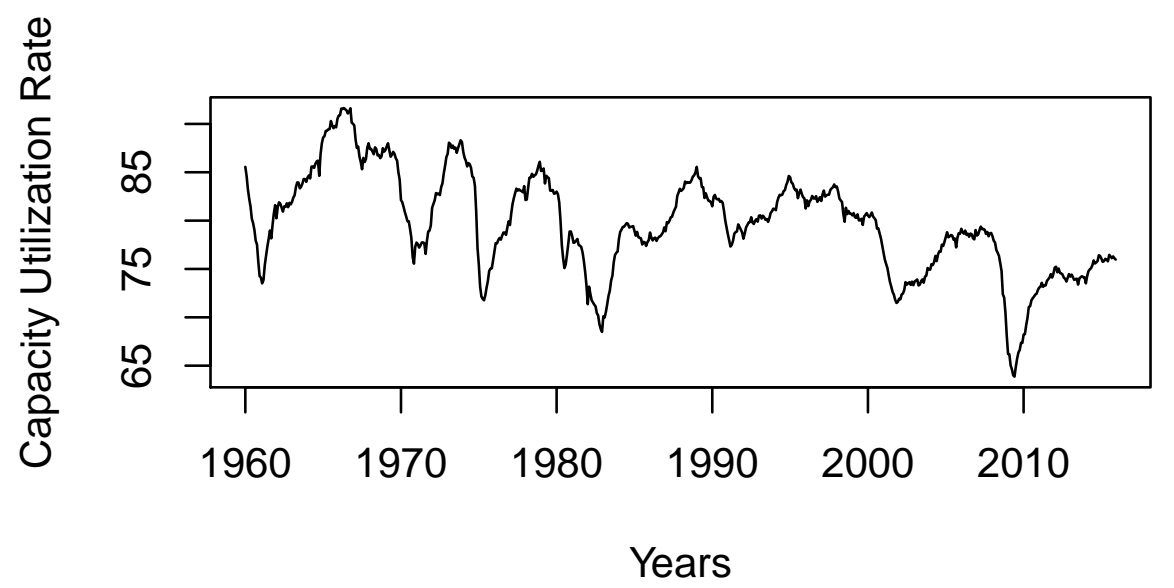

Figure 1: Capacity Utilization in the US, 1960-2015

Beyond this clear trend, it is also possible to establish a further empirical relationship between the level of $u$ and its standard deviation, which is less evident in the graph above.

\footnotetext{
8 Nikiforos (2016, pp.444-5) rejects the claim that there exists a negative trend in the FRED capacity utilization data. This interpretation is not based on statistical analysis of the trend itself, however (on which see Avritzer (2019)). Nikiforos (2016) also favours an interpretation of the data presented in Figure 1 that distinguishes between discrete periods or episodes characterized by different mean values. As will soon become clear, this is similar to our own preferred interpretation of the data. We do not, therefore, seek to emphasize the differences between our own interpretation of Figure 1 and that of Nikiforos (2016), which may be more apparent than real - or at most, differences of degree rather than kind.
} 
However, this relationship becomes clearer in Table 1, which presents the mean and standard deviations of both the actual and de-trended values of the capacity utilization rate for five discrete time periods: two longer periods of boom and "tranquility", from 1960 to 1972 (the Golden Age upswing) and from 1991 to 2006 (the Neoliberal upswing); and two shorter periods of crisis, from 1973 to 1975 (the demise of the Golden Age upswing) and from 2007 to 2009 (the demise of the Neoliberal upswing). By distinguishing between discrete periods in this fashion, we are following long-established traditions in heterodox macroeconomics associated, inter alia, with the Regulation and Social Structure of Accumulation schools, together with individual authors such as Minsky (1986) and Cornwall (1990) - suggesting that capitalism evolves through discrete stages or episodes. According to this vision, long-term growth dynamics are characterized by long and slow builds, embedded in historically-specific institutional frameworks, during which intervals confidence and animal spirits improve gradually. These long booms are punctuated (and thus brought to an end) by sudden and severe crises that simultaneously fracture the institutional framework on which the previous upswing was based and give rise to sudden and potentially persistent diminutions of confidence and animal spirits 9

Table 1 reveals that the mean of the actual capacity utilization rate decreases over time, consistent with the negative time trend observed in Figure 1. It also demonstrates that as the economy transitions from long periods of boom and tranquility to short periods of crisis, the mean of the actual capacity utilization rate falls and its standard deviation rises. In other words, abstracting from the trend decline in the mean actual rate of capacity utilization, there is a tendency for the mean rate of capacity utilization to fall, and its standard deviation

\footnotetext{
${ }^{9}$ See, for example, Guttmann (2015) for a recent account of this thinking.

The reader will note that in addition to the discrete periods mentioned in the text, Table 1 also reports means and standard deviations for the 1976-1990 period. In the literature just noted, on which our treatment of the data is based, this is considered a period of interregnum between the breakdown of the Golden Age and the emergence of Neoliberalism and is largely set aside in what follows as being representative of neither a period of boom and tranquility nor one of crisis.
} 
Table 1: Mean and Standard Deviation of Capacity Utilization in the US for Selected Periods, $1960-2015$

\begin{tabular}{lcccc}
\hline Period & $\begin{array}{c}\text { Mean } \\
(u)\end{array}$ & $\begin{array}{c}\text { Standard } \\
\text { Deviation } \\
(u)\end{array}$ & $\begin{array}{c}\text { Mean } \\
\left(u_{D T}\right)\end{array}$ & $\begin{array}{c}\text { Standard } \\
\text { Deviation } \\
\left(u_{D T}\right)\end{array}$ \\
& & & & \\
\hline \hline & & & & \\
$1960-1972$ & 83.86 & 4.53 & 79.79 & 4.66 \\
$1973-1975$ & 81.94 & 6.32 & 79.44 & 6.18 \\
$1976-1990$ & 79.63 & 4.05 & 78.80 & 4.20 \\
$1991-2006$ & 79.06 & 3.31 & 81.10 & 2.94 \\
$2007-2009$ & 73.10 & 5.91 & 76.89 & 5.77 \\
& & & & \\
\hline
\end{tabular}

to rise, in the crises that end long booms in the US economy.

These observation are borne out by the mean and standard deviation of the de-trended rate of capacity utilization $\left(u_{D T}\right)$ that are also reported in Table 1 (see Figure 2 for illustration of the month-to-month values of the de-trended rates of capacity utilization used to calculate these first and second moments) 10 The long periods of boom and tranquility (1960-72 and 1991-2006) are characterized by peaks in the mean value of $u_{D T}$ and troughs in its standard deviation. Meanwhile, the crises that bring these longer periods of boom and tranquility to

${ }^{10}$ The data in Figure 2 were de-trended by first estimating a linear regression of the form:

$$
u=\beta_{0}+\beta_{1} t+\epsilon
$$

where $t$ denotes the time period, from which were calculated estimated values of the capacity utilization rate:

$$
\hat{u}=\hat{\beta}_{0}+\hat{\beta}_{1} t
$$

Finally, the de-trended rate of capacity utilization was calculated as:

$$
u_{D T}=(u-\hat{u})+E(u)
$$


a close (1973-75 and 2007-09) are marked by a drop in the mean and a rise in the standard deviation of $u_{D T}$.

These results are not altogether surprising. They suggest that as a long boom ends and the economy enters a crisis, the level of macroeconomic performance deteriorates and this is accompanied by an increase in the volatility of the macroeconomic environment. Macroeconomic volatility drops, meanwhile, when the economy eventually reconstitutes an institutional framework capable of fostering buoyant animal spirits and improved macroeconomic performance. In other words, variations in performance between successive discrete episodes of boom and crisis suggest that, as a first approximation of the stylized facts, we have:

$$
\sigma_{u}^{2}=f(u) \quad, \quad f^{\prime}<0
$$

As we will subsequently see, this relationship is important for providing a behavioural foundation for hysteresis in the normal rate of capacity utilization.

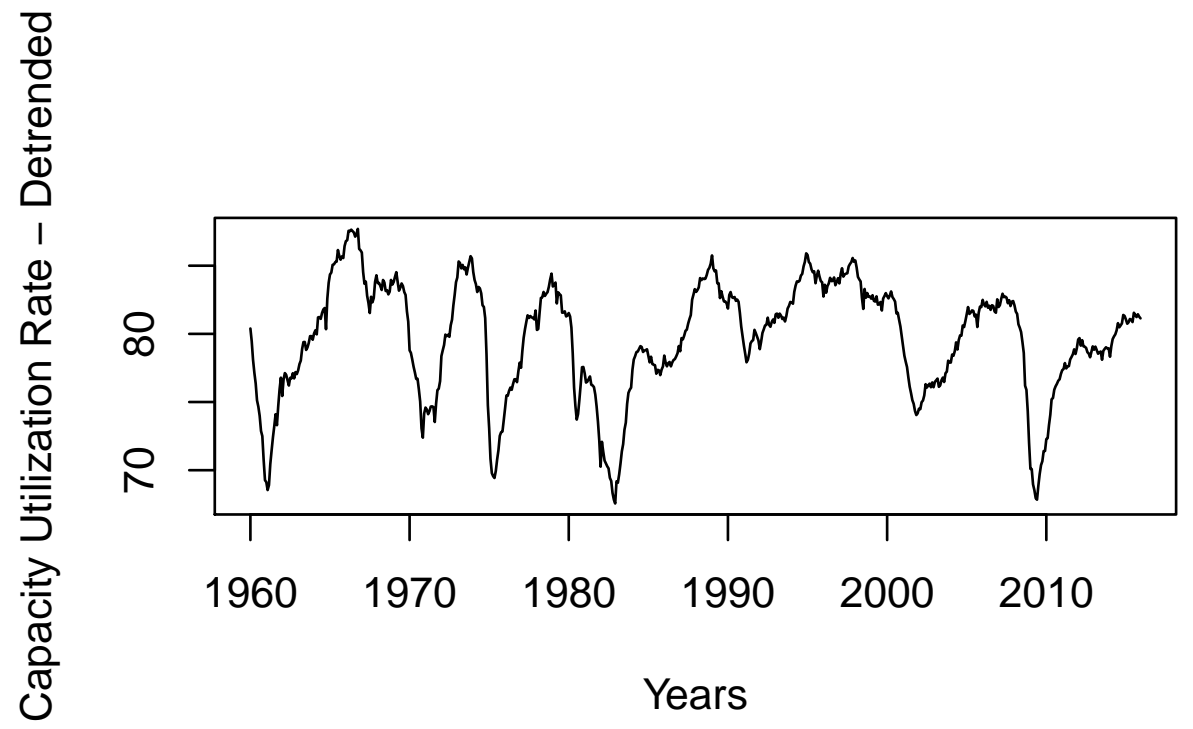

Figure 2: De-trended Capacity Utilization in the US, 1960-2015 


\subsection{Estimating the normal rate of capacity utilization}

As noted, we use the HP filter to estimate the trend rate of capacity utilization rate data, which we then interpret as the normal rate of capacity utilization. Both the trend and cyclical components of the FRB capacity utilization data thus obtained appear in Figure 3. It can be seen that there is a distinct "trend in the trend" in Figure 3- specifically, a decline in the HP trend (i.e., normal) capacity utilization rate over time, suggesting that the latter is not mean-reverting. There is also substantial variation in the HP trend (normal) rate of capacity utilization over time, around this downward trend.

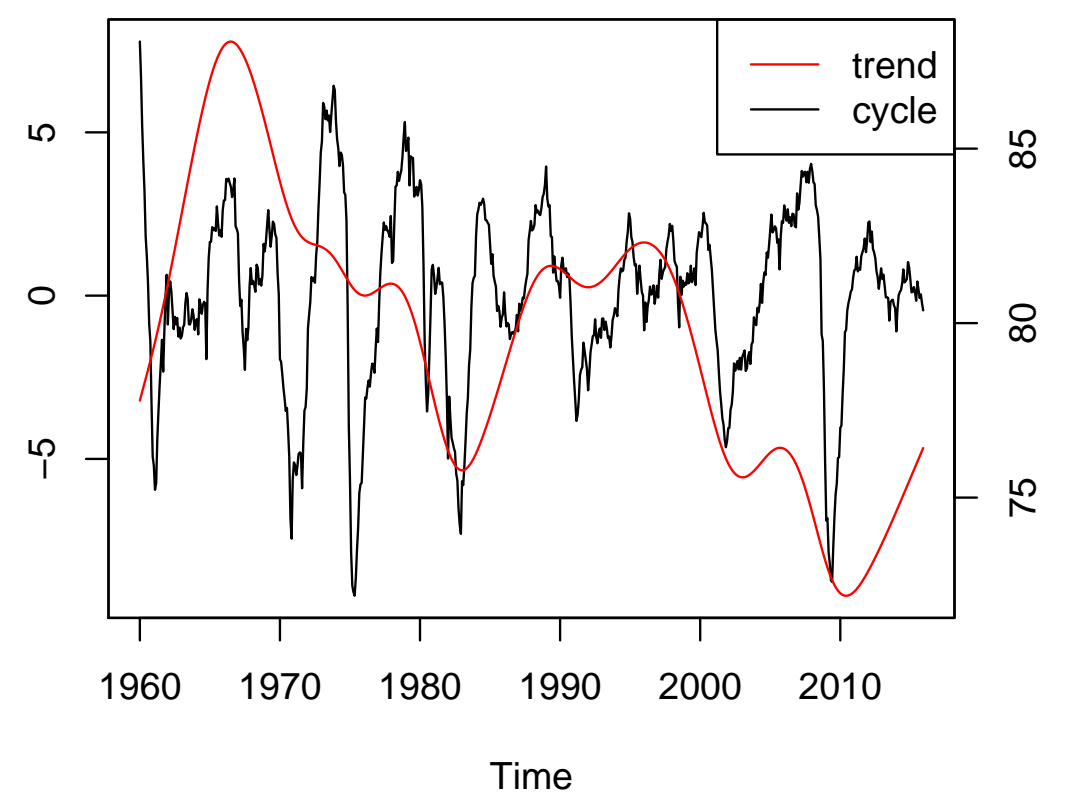

Figure 3: Trend and Cycle in US Capacity Utilization, 1960-2015

Using the trend and cycle components generated from the HP filter using monthly data, two new data series are then created. First, we calculate an annual mean value of the trend, henceforth referred to as the estimated normal rate of capacity utilization, $\hat{u}_{n}$. Next, we 
calculate annual values of the variance of the cycle, referred to hereafter as $\sigma_{c y c l e}^{2}$. These two new series were calculated on an annual basis because of the need to use multiple monthly observations in order to calculate a value for the variance of the cyclical component. Figure 4 shows both of the annualized series used in what follows to analyse the relationship between the trend (normal) rate of utilization and macroeconomic volatility. Figure 4 shows that while there is a trend in the normal rate of utilization (as noted above), there is no similar trend in the variance of the cycle. This observation must be taken into account when examining the relationship between these variables.

Mean of Trend

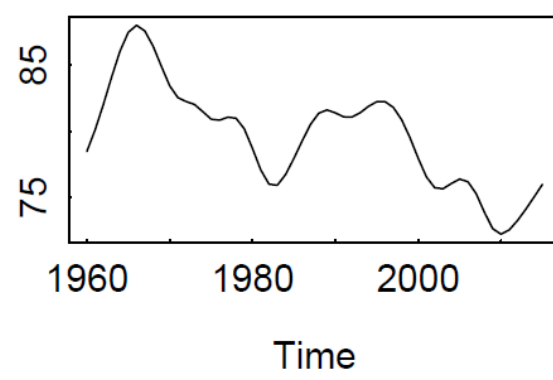

Variance of Cycle

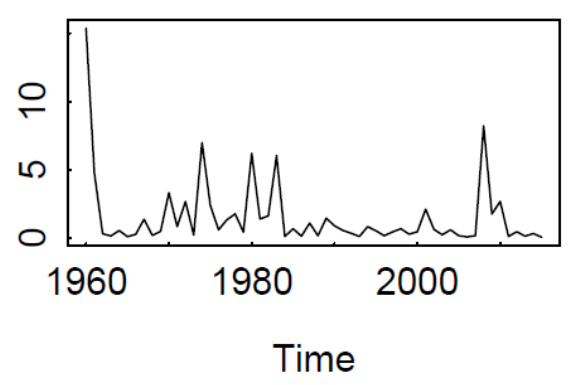

Figure 4: Trend and Variance of Cycle in US Capacity Utilization, 1960-2015

\subsection{Estimated relationships between the mean of the trend and the variance of the cycle}

Since it is possible to observe a clear trend in one of the series plotted in Figure 4 , both series were tested for unit roots using the Dickey Fuller unit root test. Tables 2 and 3 present the results of the test. Based on these tests we can conclude unequivocally that while $\hat{u}_{n}$ has a unit root, the variance of the cycle is $I(0)$. Notice also that the low absolute value of the DF statistic on which the finding of non-stationarity of the normal rate is based reduces the 
possibility of a type II error.

Table 2: Critical Values for the Dickey-Fuller Unit Root Test

\begin{tabular}{llll}
\hline & $1 \%$ & $5 \%$ & $10 \%$ \\
& & & \\
\hline \hline$\tau_{1}$ & -2.60 & -1.95 & -1.61 \\
\hline
\end{tabular}

Table 3: Dickey-Fuller Test Results

Trend Variance

of Cycle

\begin{tabular}{lll}
\hline \hline & & \\
Dickey-Fuller & & \\
Test Statistic & -0.52 & -4.80 \\
& & \\
\hline
\end{tabular}

Bearing in mind the DF test statistics reported above, we now estimate two models that both account for the different orders of integration of the estimated normal rate and of the variance of the cycle. In both models the estimation method is Ordinary Least Squares (OLS).

In Model 1 the estimating equation is: $\hat{u}_{n}=\alpha+\beta \sigma_{\text {cycle }}^{2}+\gamma t$ where $\hat{u}_{n}$ is the annual average value of the HP filter trend illustrated in Figure 3, and $\sigma_{\text {cycle }}^{2}$ is the annual variance of the cycle also illustrated in the same figure. The time trend, $t$, controls for the trend in $\hat{u}_{n}$. The results of this estimation are presented in Table 4. In Model 2 the estimating 
equation is $\Delta \hat{u}_{n}=\alpha+\beta \sigma_{\text {cycle. }}^{2}$. Here, $\Delta \hat{u}_{n}$ is the $I(0)$ first difference of the non-stationary estimated variable $\hat{u}_{n}$. The results of this estimation are presented in Table 5 .

Table 4: Estimation Results

\begin{tabular}{lcccc}
\hline & Coefficient & Std. Error & $t$-value & $\operatorname{Pr}(>|t|)$ \\
\hline \hline & & & & \\
$\hat{\alpha}$ & 86.35 & 0.69 & 125.60 & 0.00 \\
$\hat{\sigma}_{\text {cycle }}^{2}$ & -0.53 & 0.12 & -4.45 & 0.00 \\
$t$ & -0.21 & 0.02 & -10.81 & 0.00 \\
& & & & \\
\hline
\end{tabular}

Table 5: Estimation Results (cont.)

\begin{tabular}{lcccc}
\hline & Coefficient & Std. Error & $t$-value & $\operatorname{Pr}(>|t|)$ \\
\hline \hline & & & & \\
$\hat{\alpha}$ & 0.17 & 0.16 & 1.05 & 0.30 \\
$\hat{\sigma}_{\text {cycle }}^{2}$ & -0.16 & 0.07 & -2.31 & 0.03 \\
\hline
\end{tabular}

The results in Tables 4 and 5 show that there is a significant inverse relationship between the mean of the HP trend and the variance of the cycle. In other words, when the nonstationarity of $u_{n}$ is properly controlled for, it seems that there is a significant relationship between the estimated normal rate of capacity utilization and the variance of short run fluctuations in the actual rate of capacity utilization. We can therefore conclude that the variability of the actual capacity utilization rate influences the normal rate, or in other words, 
as a stylized fact:

$$
u_{n}=g\left(\sigma_{u}^{2}\right) \quad, \quad g^{\prime}<0
$$

\section{Hysteresis in the normal rate of capacity utilization: a behavioural explanation}

According to the stylized facts presented in the previous section, we have:

$$
\begin{array}{ll}
\sigma_{u}^{2}=f(u) \quad, \quad f^{\prime}<0 \\
u_{n}=g\left(\sigma_{u}^{2}\right) \quad, \quad g^{\prime}<0
\end{array}
$$

The interpretation of equation (7) is (as previously noted) intuitive: crises that, by definition, are associated with a deterioration of macroeconomic performance are also associated with greater macroeconomic volatility, whereas periods of boom are also periods of macroeconomic tranquility. Interpretation of equation (8), meanwhile, is related to the Steindlian notion of why we have a $u_{n}<1$ in the first place: firms maintain a conventional degree of excess capacity to insulate themselves against losses of market share arising from unforeseen variations in product demand in an environment of fundamental uncertainty. According to Steindl (1952, pp.9-14), the deliberate or planned creation of excess capacity by firms (as opposed to the experience of actual and possibly undesired excess capacity brought about by variations in aggregate demand) can be attributed to two things. One is the need to "build ahead of demand" in an environment in which the economy is growing continuously but capital investments are discrete and "lumpy", making incremental expansions of capacity in response to incremental expansions in the size of the market difficult. Another is the desire to hedge against potential loss of market share due to unforeseen variations of demand. Hence: 
It is surprising that ... equilibrium excess capacity should never have been dealt with in the same way as other forms of idle reserves, for example, stocks of commodities or balances of money. It would then have to be explained as a reserve held in anticipation of future events, or in view of some existing uncertainty ... [Hence] the first reason [for deliberately holding excess capacity] suggests itself very easily by the existence of fluctuations in demand. The producer wants to be in on a boom first, and not to leave the sales to new competitors who will press on his market when the good time is over. (Steindl, 1952, p.9)

Note that, as such, and pace Nikiforos (2016, p.444, emphasis added), there is no sense in which $u_{n}$ can (or should) be regarded as "mere convention". Conventions are the acme of decision making under uncertainty, playing a vital role in informing behaviour when optimal responses cannot be fathomed. Conventions, moreover, are frequently informed by actual events - in this case (per equation (88)), the actual volatility of demand corresponding (per equation (7p) to the actual level of capacity utilization - suggesting the possibility that changes in conventions are related to changes in actual events (albeit possibly in discontinuous and asymmetric fashion).11 As noted by Lavoie (1992, pp.330-1), authors such as Amadeo (1987, p.79) have previously used the relationship between the normal rate of capacity utilization and the variance of demand conditions as an argument in favour of a constant normal rate, on the grounds that the variance of demand can be taken as given. This is equivalent to replacing equation (7) above with the alternative closure:

$$
\sigma_{u}^{2}=\bar{\sigma}_{u}^{2}
$$

But as demonstrated by the review of stylized facts in the previous section, across different discrete phases or episodes of growth and crisis, this alternative closure cannot be justified. Variation in the variance of demand conditions thus becomes a basis for variation in the normal rate of capacity utilization that is true to the Steindlian roots of the very existence

\footnotetext{
${ }^{11}$ This notion of discontinuous change is consistent with the interpretation of the stylized facts presented earlier, but is not captured by the continuous function $g($.$) in equation (8), which must therefore be considered$ a first approximation. We return to the theme of discontinuity below.
} 
of $u_{n}<1.12$

In sum, equations (7) and (8) together suggest that an increase (decrease) in $u$ is accompanied by a decrease (increase) in $\sigma_{u}^{2}$ - i.e., that higher (lower) $u$ is associated with lower (higher) $\sigma_{u}^{2}$ and hence less (more) uncertainty about $u$. Given that uncertainty about demand conditions is the basic Steindlian motivation for firms to plan to operate with excess capacity (i.e., to set $u_{n}<1$ ), it follows that an increase in uncertainty can induce a lower value of $u_{n}$ to accommodate bigger potential future variations in demand and hence realized capacity utilization rates. Ultimately, $u_{n}$ varies directly with $u$ via the intermediary relationship of both variables to $\sigma_{u}^{2}$. This is summarized by the reduced form of equations (7) and (8), written as:

$$
u_{n}=h(u) \quad, \quad h^{\prime}>0
$$

Now note that equation (9) with $h^{\prime}>0$ suggests that equation (5) is, in fact, a sensible first approximation ${ }^{13}$ This is easily demonstrated by appeal to equation (5) itself. Hence note that by introducing lags, we can re-write equation (5) as:

$$
\begin{gathered}
\Delta u=u_{n t}-u_{n t-1}=\mu\left(u_{t}-u_{n t-1}\right) \\
\left.\Rightarrow u_{n t}=\mu u_{t}-(1-\mu) u_{n t-1}\right) \\
\Rightarrow u_{n}=h(u) \quad, \quad h^{\prime}>0
\end{gathered}
$$

According to Nikiforos (2016, p.444, emphasis added), "Behaviour of the desired utilization rate as described in equation [5], based on the need for the firm to face unexpected demand,

\footnotetext{
${ }^{12}$ Ironically this argument is anticipated by Skott $(2012$, p.116) as the basis of potential time-variation in the normal rate of capacity utilization. However, like Amadeo (1987), Skott does not anticipate the link between $u$ and $\sigma_{u}^{2}$ in equation (7) and hence, ultimately, the connection between $u$ and $u_{n}$. See also Nikiforos (2016, p.445).

${ }^{13}$ We say first approximation because, once again, we have yet to take proper account of the discontinuity of the relationship between $u$ and $\sigma_{u}^{2}$ suggested by the stylized facts
} 
would mean that when the actual rate of utilization is lower than the desired rate, the firm expects more volatile demand and thus decreases its desired rate of utilization. It is hard to see why this would happen." Our hope is that on the basis of the analysis thus far, the reader is by now persuaded that this last claim cannot be regarded as valid.

However, there remains the matter that equations (7) and (8) provide a continuous representation of relationships arising between discrete macroeconomic regimes of long boom and crisis identified in our discussion of the stylized facts. This suggests that in order to properly articulate a behavioural theory of hysteresis in the normal rate consistent with the stylized facts, we need to go beyond the first approximation in equation (5) and develop a non-linear model. This can be done by appeal to the theory of true or strong hysteresis (Cross, 1993; Amable et al., 1994, Lang, 2008). Figure 5 provides a "structuralist" (onesector) representation of a non-ideal relay, a technology that is commonly used to represent the behaviour of the (assumed heterogeneous) parts of a strong hysteretic system. In Figure 5. the lower arm of the non-deal relay corresponds to a high value of the normal rate of capacity utilization $\left(u_{n H}\right)$ that prevails when macroeconomic volatility is sufficiently low specifically, when $\sigma_{u}^{2}<\sigma_{u H}^{2}=f\left(u_{L}\right)$, where $u_{L}$ denotes a low (crisis) rate of capacity utilization associated with a high (crisis) level of macroeconomic volatility $\left(\sigma_{u H}^{2}\right)$ sufficient to induce firms, as a result of their increased uncertainty perception and/or aversion accompanying the crisis conditions just described, to switch to a low value of the normal rate of capacity utilization, $u_{n L}$. The latter is designed to insulate firms against unexpected adverse effects on their market share brought about by the observed increase in macroeconomic volatility. As the economy recovers, $u$ rises and $\sigma_{u}^{2}$ falls, but the economy remains on the upper-arm of the non-ideal relay in Figure 5 corresponding to $u_{n}=u_{n L}$ until and unless volatility falls to $\sigma_{u L}^{2}$, at which point firms switch back to the lower arm of the non-ideal relay as they revert to $u_{n}=u_{n H}$ in the belief that a higher normal rate suffices once again in the now sufficiently recovered (and hence low volatility) macroeconomic environment. As is clear 
from inspection of Figure 5 , modest variations in $\sigma_{u}^{2}$ do not induce changes in $u_{n}$. However, extreme variations in volatility - associated with the sudden onset of crisis, for example, or the eventual forgetting of crisis conditions that accompanies the subsequent onset of long booms - can induce variation in the normal rate, and (following Steindl (1952)) for reasons associated with those that give rise to $u_{n}<1$ in the first place.

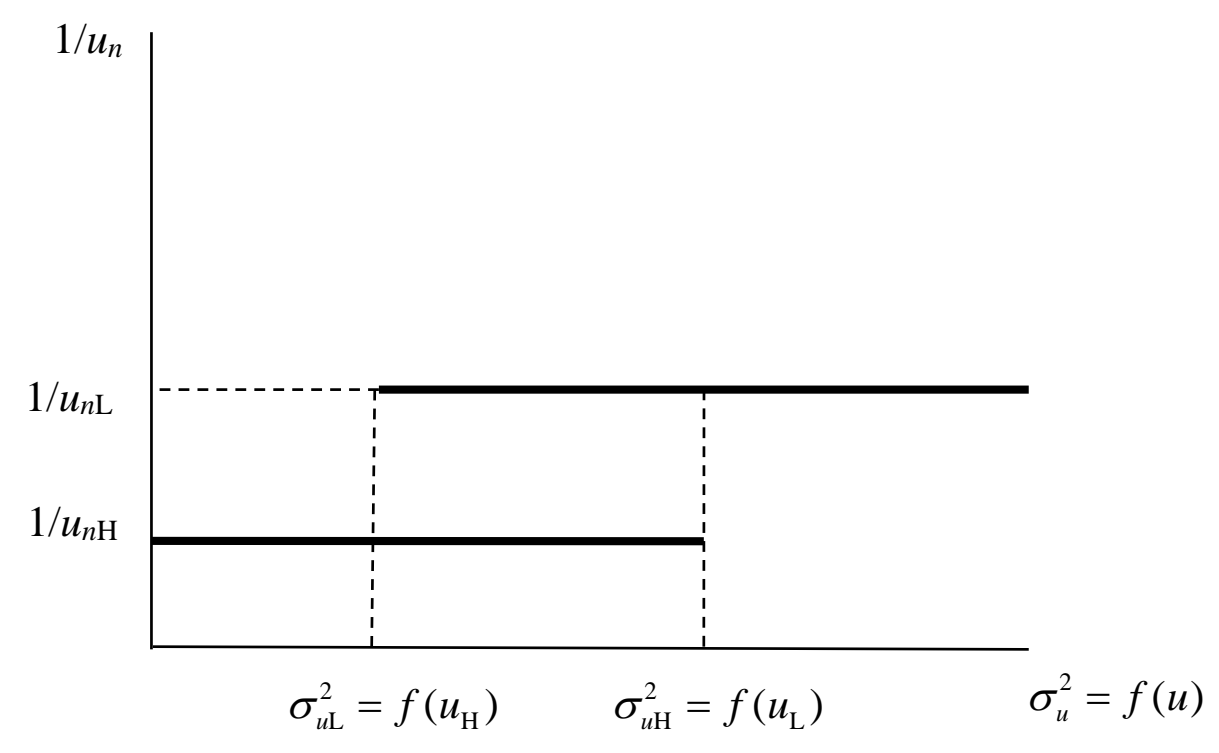

Figure 5: Hysteresis in the normal rate of capacity utilization

A concrete historical example related to the stylized facts discussed previously may assist the reader with interpretation of Figure 5 . As demonstrated in Table 1 , the end of the Golden Age upswing in 1973-75 crisis led to reduction in $u$ and sudden spike in macroeconomic volatility. The latter can be interpreted as setting $\sigma_{u}^{2}>\sigma_{u H}^{2}$ in Figure 5 , with the result that $u_{n}$ fell to $u_{n L}$. According to Table 1, this spike in volatility was short lived - but $\sigma_{u}^{2}$ did not diminish sufficiently (during the period of inter regnum 1976-90) to set $\sigma_{u}^{2}<$ $\sigma_{u L}^{2}$ and so restore $u_{n}$ to $u_{n H}$ in Figure 5. The low normal rate $\left(u_{n}=u_{n L}\right)$ therefore persisted - and would, in fact, have persisted indefinitely if, despite future variation in macroeconomic performance and its volatility, we had continued to observe $\sigma_{u}^{2}>\sigma_{u L}^{2}$ in 
all future periods ${ }^{14}$ Gradually, however, and as a consequence of developments during the period of inter regnum following the 1973-75 crisis, the restoration of an institutional framework and level of confidence conducive to rapid growth (i.e., the onset of Neoliberalism after 1990) raised $u$ and reduced $\sigma_{u}^{2}$ such that $\sigma_{u}^{2}<\sigma_{u L}^{2}$, resulting in an increase in $u_{n}$ to $u_{n H}$. Another long-upswing-ending crisis (the Great Recession) can then be interpreted as having reduced $u$ and raised $\sigma_{u}^{2}$ such that $\sigma_{u}^{2}>\sigma_{u H}^{2}$, reducing the normal rate of capacity utilization to $u_{n}=u_{n L}$ once again.

Appeal to the analytical structure of strong hysteresis suggests that we can go much further than the simple structuralist representation of this process in Figure 5 , by allowing for sectoral or even firm-specific values of the critical threshold values of $\sigma_{u}^{2}, \sigma_{u L}^{2}$ and $\sigma_{u H}^{2}$. This would give rise to a micro-founded strong hysteretic model of the normal rate of capacity utilization which would, in turn, permit continuous variation in the average or economywide normal rate (akin to that observed in the behaviour of the trend in observed capacity utilization associated with variation in the normal rate in Figure 3), even as variation in the normal rate at sectoral (or firm) level remains discontinuous (as depicted in Figure 5).15 We leave this to further research.

In the meantime, note that even in its simplified structuralist state, our representation of the behavioural basis for hysteresis in the normal rate of capacity utilization addresses the first, third, and fourth criticisms levelled against equation (5) by Skott (2012) ${ }^{16}$ In the first place, our model provides a behavioural foundation for equation (5), as a first approximation of a process that links changes in the normal rate of capacity utilization to

\footnotetext{
${ }^{14}$ In other words, temporary events - in this case a short-lived increase in $\sigma_{u}^{2}$ during a brief but profound (long-upswing-ending) crisis - can have permanent effects, ceteris paribus. This is a basic property of hysteresis which is hereby related to endogenously-induced variation in the normal rate of capacity utilization.

${ }^{15}$ The critical feature required to create this outcome is simply heterogeneity among the "parts" (sectors or firms) of which the economy as a whole is comprised. This appears to be a modest requirement - see, for example, Setterfield (2019, pp.456-60).

${ }^{16}$ Recall the second criticism in not relevant for our purposes since it is directed at an entry-deterrencebased argument specific to Dutt (1997).
} 
changes in macroeconomic volatility across different macroeconomic regimes associated with higher or lower average actual capacity utilization rates. This behavioural foundation recalls the original behavioural justification for the existence of a $u_{n}<1$ in Steindl (1952), which is rooted in conventional behaviour in response to decision making in an environment of uncertainty. Furthermore, the limited and discontinuous adjustments in $u_{n}$ in our model suggest that variation in the normal rate of capacity utilization is both bounded (confined to the range $u_{n L}-u_{n H}$ in Figure 5) and subject to discrete as opposed to continuous, moment-by-moment change. Finally, it follows from our strong hysteretic model of $u_{n}$ that we would expect variation in the normal rate of capacity utilization to occur at low frequency, in response to some but not all changes in the macroeconomic environment captured by variations in $u$ and $\sigma_{u}^{2}$. In other words, the normal rate will present itself as a slow adjusting variable relative to the higher-frequency changes in the actual macroeconomic environment.

\section{Conclusions}

Kaleckians seeking to reconcile the possibility of wage-led growth in the long run with the Classical notion of a fully adjusted position have invoked hysteresis in the normal rate of capacity utilization as a basis for explaining how long-run variation in the capacity utilization rate can be made consistent with equalization of the actual and normal rates of capacity utilization. This hysteresis argument has been criticized in various quarters as lacking behavioural foundations. In this paper, we have demonstrated that the notion of hysteresis in the normal rate of capacity utilization can be given a behavioural foundation that is closely related to the basis - per Steindl $(1952)$ - for the very existence of $u_{n}<1$. This behavioural theory follows from a review of the stylized facts of US capitalism, which suggests that the normal rate of capacity utilization varies with the actual rate as a result of the relation-

ship between both of these variables and macroeconomic volatility. Discontinuities in the 
relationships between these variables suggest that future research should focus on modelling endogenous variation in the normal rate of capacity utilization as a process of strong hysteresis, characterized by heterogeneity at the meso- and/or microeconomic levels in both actual and normal rates of capacity utilization and exposure to macroeconomic volatility.

\section{References}

Amable, B., J. Henry, F. Lordon, and R. Topol (1993). Unit root in the wage-price spiral is not hysteresis in unemployment. Journal of Economic Studies 20(1/2), 123-135.

Amable, B., J. Henry, F. Lordon, and R. Topol (1994). Strong hysteresis versus zero-root dynamics. Economics Letters 44(1-2), 43-47.

Amadeo, E. (1986). The role of capacity utilization in long-period analysis. Political Economy 2, 147-85.

Amadeo, E. (1987). Expectations in a steady-state model of capacity utilization. Political Economy: Studies in the Surplus Approach 3(1), 75-89.

Avritzer, J. D. (2019). Three Essays on Income Distribution, Growth and Household Debt Dynamics. Ph. D. thesis, New School for Social Research, New York, in progress.

Blecker, R. (2016). Wage-led versus profit-led demand regimes: the long and the short of it. Review of Keynesian Economics 4(4), 373-390.

Cassetti, M. (2006). A note on the long-run behaviour of Kaleckian models. Review of Political Economy 18(4), 497-508.

Commendatore, P. (2006). Are Kaleckian models relevant for the long run? In N. Salvadori and C. Panico (Eds.), Classical, Neoclassical and Keynesian Views on Growth and Distribution. Cheltenham: Edward Elgar.

Cornwall, J. (1990). The Theory of Economic Breakdown: An Institutional-Analytical Approach,. Oxford: Basil Blackwell.

Cross, R. (1993). On the foundations of hysteresis in economic systems. Economics and Philosophy 9(1), 53-74.

Dallery, T. and T. van Treeck (2011). Conflicting claims and equilibrium adjustment processes in a stock-flow consistent macroeconomic model. Review of Political Economy 23(2), 189-211.

Dumenil, G. and D. Levy (1999). Being Keynesian in the short term and classical in the long term: The traverse to classical long-term equilibrium. Manchester School 67(6), 684-716. 
Dutt, A. K. (1990). Growth, Distribution and Uneven Development. Cambridge: Cambridge University Press.

Dutt, A. K. (1997). Equilibrium, path dependence and hysteresis in post-Keynesian models. In P. Arestis, G. Palma, and M. Sawyer (Eds.), Capital Controversy, Post-Keynesian Economics and the History of Economic Thought: Essays in Honour of Geoff Harcourt. London: Routledge.

Dutt, A. K. (2010). Equilibrium, stability and path dependence in Post Keynesian models of economic growth. In A. Birolo, D. Foley, H. D. Kurz, B. Schefold, and I. Steedman (Eds.), Production, Distribution and Trade: Alternative Perspectives. Essays in Honour of Sergio Parrinello. London: Routledge.

Eichner, A. S. (1976). The Megacorp $\&$ Oligopoly: Micro Foundations of Macro Dynamics. Cambridge, UK: Cambridge University Press.

Freitas, F. and F. Serrano (2015). The Sraffian supermultiplier as an alternative closure to heterodox growth theory. Technical report, Instituto de Economia, Universidade Federal do Rio de Janeiro (UFRJ).

Guttmann, R. (2015). The heterodox notion of structural crisis. Review of Keynesian Economics 3(2), $194-212$.

Hamilton, J. D. (2018). Why you should never use the Hodrick-Prescott filter. The Review of Economics and Statistics 100(5), 831-843.

Harcourt, G. C. (1972). Some Cambridge Controversies in the Theory of Capital. Cambridge, UK: Cambridge University Press.

Hein, E., M. Lavoie, and T. van Treeck (2011). Some instability puzzles in Kaleckian models of growth and distribution: a critical survey. Cambridge Journal of Economics 35(3), $587-612$.

Hein, E., M. Lavoie, and T. van Treeck (2012). Harrodian instability and the "normal rate' of capacity utilization in Kaleckian models of distribution and growth - a survey. Metroeconomica 63(1), 139-169.

Kaldor, N. (1985). Economics without Equilibrium. Armonk, NY: M.E. Sharpe.

Lang, D. (2008). Why economists should choose their inheritance: Physics and pathindependence in economic systems. Review of Political Economy 20(3), 405-420.

Lavoie, M. (1992). Foundation of Post-Keynesian Economic Analysis. Cheltenham, UK: Edward Elgar.

Lavoie, M. (1995). The Kaleckian model of growth and distribution and its Neo-Ricardian and Neo-Marxian critiques. Cambridge Journal of Economics 19(6), 789-818. 
Lavoie, M. (1996). Traverse, hysteresis and normal rates of capacity utilization in kaleckian models of growth and distribution. Review of Radical Political Economics 28(4), 113-147.

Lavoie, M. (2002). The Kaleckian growth model with target return pricing and conflict inflation. In M. Setterfield (Ed.), The Economics of Demand-led Growth. Cheltenham: Edward Elgar.

Lavoie, M. (2003). Kaleckian effective demand and Sraffian normal prices: Towards a reconciliation. Review of Political Economy 15(1), 53-74.

Lavoie, M. (2010). Surveying short-run and long-run stability issues with the Kaleckian model of growth. In M. Setterfield (Ed.), Handbook of Alternative Theories of Economic Growth,. Cheltenham, UK: Edward Elgar.

Lavoie, M. (2016). Convergence towards the normal rate of capacity utilization in NeoKaleckian models: The role of non-capacity creating autonomous expenditures. Metroeconomica $67(1)$, 172-201.

Lavoie, M., G. Rodríguez, and M. Seccareccia (2004). Similitudes and discrepancies in postKeynesian and Marxist theories of investment: A theoretical and empirical investigation. International Review of Applied Economics 18(2), 127-149.

Minsky, H. P. (1986). Stabilizing an Unstable Economy. New Haven, CT: Yale University Press. As reprinted in 2008 by McGraw-Hill (New York, NY).

Nikiforos, M. (2016). On the 'utilisation controversy': a theoretical and empirical discussion of the Kaleckian model of growth and distribution. Cambridge Journal of Economics 40(2), 437-467.

Robinson, J. (1956). The Accumulation of Capital. London: Macmillan.

Schoder, C. (2012). Hysteresis in the Kaleckian growth model: A Bayesian analysis for the US manufacturing sector from 1984 to 2007. Metroeconomica 63(3), 542-568.

Schüler, Y. S. (2019). How should we filter economic time series? Available at SSRN: http://dx.doi.org/10.2139/ssrn.3366923.

Setterfield, M. (2019). Long-run variation in capacity utilization in the presence of a fixed normal rate. Cambridge Journal of Economics 43(2), 443-463.

Shaikh, A. (2009). Economic policy in a growth context: a classical synthesis of Keynes and Harrod. Metroeconomica 60(3), 455-494.

Skott, P. (2010). Growth, instability and cycles: Harrodian and Kaleckian models of accumulation and income distribution. In M. Setterfield (Ed.), Handbook of Alternative Theories of Economic Growth. Cheltenham: Edward Elgar. 
Skott, P. (2012). Theoretical and empirical shortcomings of the Kaleckian investment function. Metroeconomica 63(1), 109-138.

Steindl, J. (1952). Maturity and Stagnation in American capitalism. Oxford, UK: Blackwell. 